\title{
The effects of vanadyl sulfate on glutathione, lipid peroxidation and nonenzymatic glycosylation levels in various tissues in experimental diabetes
}

\author{
Sevim Tunalı ${ }^{1}$, Refiye Yanardağ ${ }^{1}$ \\ 'Istanbul University-Cerrahpasa, Faculty of Engineering, Department of Chemistry, Istanbul, Turkey
}

ORCID IDs of the authors: S.T.0000-0003-3363-1290; R.Y. 0000-0003-4185-4363

Cite this article as: Tunali, S., \& Yanardag, R. (2021). The effects of vanadyl sulfate on glutathione, lipid peroxidation and nonenzymatic glycosylation levels in various tissues in experimental diabetes. Istanbul Journal of Pharmacy, 51(1), 73-78.

\begin{abstract}
Background and Aims: Diabetes mellitus is characterized by hyperglycemia which over time leads to serious damage of several body systems. Vanadium ions and their complexes have been demonstrated to have various insulin-mimetic and antidiabetic effects. The object of the present work was to investigate the effect of vanadyl sulfate (VS) on serum total lipid and protein parameters, glutathione, lipid peroxidation and nonenzymatic glycosylation levels in cardiac, lens, lung and skeletal muscle tissues of STZ diabetic rats.

Methods: Randomly selected 6.0 - 6.5 month old Swiss Albino rats were separated into two diabetic and two control groups. A single intraperitoneal injection of $65 \mathrm{mg} / \mathrm{kg}$ streptozotocin (STZ) in $0.01 \mathrm{M}$ citrate buffer ( $\mathrm{pH}$ 4.5) was used to induce diabetes. $100 \mathrm{mg} / \mathrm{kg}$ VS was administered daily to one of the controls and one of the diabetic groups. On the 60th day of the experiment, serum total lipid and total protein levels were determined.

Results: Tissue samples were taken and used for determination of glutathione (GSH), lipid peroxidation (LPO) and nonenzymatic glycosylation (GSH) and protein levels.

Conclusion: According to the results, treatment with VS reversed the effects of diabetes by exerting antioxidant properties and preventing damage caused by diabetes on various tissues along with some serum parameters.
\end{abstract}

Keywords: Diabetes mellitus, vanadyl sulfate, oxidative stress, cardiac, lens, lung, skeletal muscle

\section{INTRODUCTION}

Diabetes mellitus (DM), caused by ineffectiveness or deficiency in the production of insulin by the pancreas, is one of the most serious chronic diseases. The expectations that 366 million people will be diabetic by 2030 shows that this disease is of tremendous importance (Li \& Lian, 2016). Two main types of diabetes stand out. Type I diabetes (DM1), in which the beta cells in the pancreas have lost ability to produce the required quantities of insulin and type II diabetes (DM2), also known as non-insulin dependent diabetes mellitus (NIDDM), in which although pancreatic beta cells produce insulin, the secretion is impared and hyperglycemia and insulin resistance develops (Domingo \& Gómez, 2016). Chronic hyperglycemia in DM causes different morphological and functional changes in various tissues (Akgun-Dar, Bolkent, Yanardag, \& Tunali, 2007; Tunali \& Yanardag, 2013; Yilmaz-Ozden et al., 2014). Diabetes, like other metabolic diseases, is associated with the development of oxidative stress and chronic inflammation. The overproduction of reactive oxygen species (ROS) in cells and tissues, is the result of the release of free radicals caused by the disruption of the oxidative and antioxidative balance. Dysfunctions in insulin secretion which occur in diabetes are closely related 
with chronic oxidative stress and impaired signaling pathways and metabolism. This leads to decreased inflammation and immunity. Therefore, insulin resistance contributes primarily to the development of diabetes and cardiovascular diseases (Newsholme, Cruzat, Keane, Carlessi, \& Bittencourt, 2016).

Vanadium is an important transition element in the fifth group of the periodic system and found in many organisms and mammalian tissues (Pal, Mani, Tripathi, \& Datt, 2018). The insulin mimetic effect of vanadium salts was first discovered in the second half of the $20^{\text {th }}$ century. According to the recommendation, vanadium salts and various vanadium compounds can replace insulin injections by administering orally at the appropriate dose in patients with DM (Heyliger, Tahiliani, \& McNeill, 1985). This has led to the development of various vanadiumbased compounds and a new field of research in the treatment of diabetes (Irving \& Stoker, 2017).

The purpose of our study was to research the antidiabetic properties of VS on total lipid parameters and total protein levels of normal and STZ diabetic rats. Also, this study explored the effect of VS on glutathione, lipid peroxidation and nonenzymatic glycosylation levels on the cardiac, lens, lung and skeletal muscle tissues of STZ diabetic rats.

\section{MATERIALS AND METHODS}

\section{Animals}

6.0 - 6.5 month old male Swiss Albino rats were examined in this research. The experiments were examined and confirmed by the Local Institute's Animal Care and Use Committees of Istanbul University. All animals were healthy and fed with the experimental animal pulp and tap water.

\section{Experimental diabetic model design}

The animals were made diabetic with a single dose of streptozotocin (STZ) $(65 \mathrm{mg} / \mathrm{kg})$ dissolved in a freshly prepared citrate buffer solution (0.01 M pH=4.5) intraperitoneally (Jound, Lambert, Stauffacher, \& Renold, 1969). Four groups were randomly created; group I untreated, nondiabetic controls ( $n=13)$; group II nondiabetic control animals administered VS ( $n=5)$; group III diabetically induced animals with STZ $(n=11)$; group IV STZinduced diabetic animals administered with VS $(n=11)$. VS was administered at a dose of $100 \mathrm{mg} / \mathrm{kg} /$ day for 60 days without interruption by gavage technique.

\section{Biochemical study and oxidative stress markers}

After STZ injection, all tail vein blood samples were regularly collected from the rats on 0, 1, 30 and 60 days (Bolkent, Bolkent, Yanardag, \& Tunali, 2005). Fasting blood glucose concentration above $200 \mathrm{mg} / \mathrm{dL}$ was considered diabetic. On the 60th day of the experiment, the animals were fasted overnight and then anesthetically sacrificed. Blood and tissue samples were taken from all groups. Blood samples were centrifuged to obtain serum for total lipid levels and protein contents were determined by the method of Frings, Fendley, Dunn, \& Queen, (1972) and the method of Lowry, Rosebrough, Farr, \& Randal, (1951) respectively. Cardiac, lens, lung, and skeletal muscle tissues were removed and frozen until the working day. The tissues were homogenized with a glass homogenizer in cold
$0.9 \%$ saline to make up 10\% (w/v) homogenate. After centrifugation, the clear upper phase was used for determination of glutathione (GSH), lipid peroxidation (LPO), nonenzymatic glycosylation (NEG) and total protein levels by the methods of Ledwozyw, Michalak, Stepien, \& Kadziolka, (1986), Beutler (1975), Parker, England, Casto, Hessel, \& Goldstein, (1981) and Lowry et al., (1951) respectively.

\section{Statistical analysis}

The unpaired t test and analysis of variance (ANOVA) were used to analyze biochemical results calculated with a statistical computer package (NCSS). The results were performed as mean \pm SD. $P<0.05$ values were accepted as significant.

\section{RESULTS}

Considerable differences in serum total lipids levels and serum total protein contents were observed as shown in Table 1. Serum total lipids levels were significantly higher in diabetic groups when compared to the control group $(P<0.0001)$. Oral administration of VS considerably decreased serum total lipids levels in the diabetic rats $(P<0.0001)$. Serum total protein levels were lower in diabetic groups in comparison with non treated controls $(P<0.0001)$. Oral VS application elevated the serum total protein levels in diabetic rats $(P<0.005)$.

\section{Table 1. Mean levels of serum lipids and protein for all groups*.}

\begin{tabular}{|c|c|c|}
\hline Groups & Total Lipid (\% mg) & Total Protein $(\% \mathrm{mg})$ \\
\hline Control & $180.35 \pm 17.85$ & $5.15 \pm 0.61$ \\
\hline $\begin{array}{l}\text { Control } \\
+ \text { VS }\end{array}$ & $207.74 \pm 20.63$ & $5.41 \pm 0.34$ \\
\hline Diabetic & $309.19 \pm 38.18^{a}$ & $3.81 \pm 0.38^{c}$ \\
\hline $\begin{array}{l}\text { Diabetic } \\
+ \text { VS }\end{array}$ & $210.28 \pm 40.52^{b}$ & $4.68 \pm 0.32^{d}$ \\
\hline$P_{\text {ANOVA }}$ & 0.0001 & 0.0001 \\
\hline \multicolumn{3}{|c|}{$\begin{array}{l}\text { * Mean } \pm S D ; \text { a } P<0.0001 \text { comparing to control group; }{ }^{b} \mathrm{P}<0.0001 \\
\text { comparing to diabetic group; }{ }^{c} \mathrm{P}<0.0001 \text { comparing to control group; } \\
{ }^{\mathrm{d} P}<0.005 \text { comparing to diabetic group. }\end{array}$} \\
\hline
\end{tabular}

\section{Cardiac tissue}

Figure 1 shows the effect of VS on GSH level of cardiac tissue. Cardiac tissue GSH level in the diabetic group was significantly decreased compared to the control group $\left({ }^{a} P<0.05\right)$. Administration of VS caused a significant increase in GSH levels in the diabetic group $\left({ }^{b} P<0.005\right)$.

The mean levels of LPO and NEG parameters are shown in Figures 2 and 3, respectively. There were remarkable increases in LPO and NEG levels in the STZ induced animals compared to untreated rats $\left({ }^{a} P<0.005\right.$, a $\left.P<0.005\right)$. It was observed that administration of VS significantly decreased both LPO and NEG levels in diabetic rats ( $\left.{ }^{\mathrm{b}} P<0.05,{ }^{\mathrm{b}} P<0.05\right)$. 


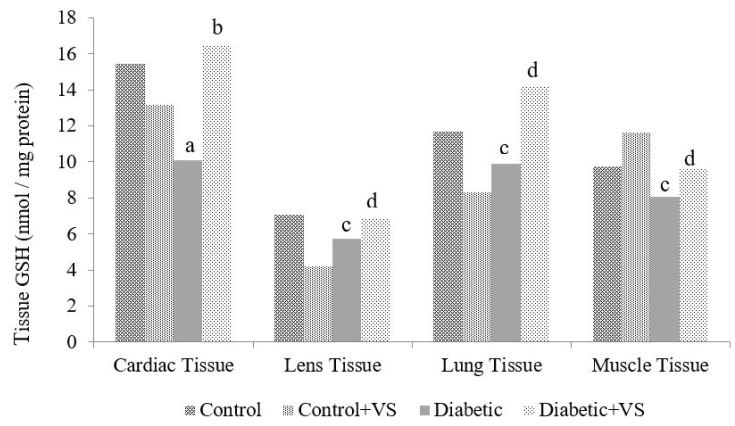

Figure 1. Effects of vanadyl sulfate on GSH levels of cardiac, lens, lung and muscle tissues for all groups.

$a p<0.05$ comparing to control group; ${ }^{b} P<0.005$ comparing to diabetic group; $c P<0.0001$ comparing to control group; $d P<0.0001$ comparing to diabetic group.

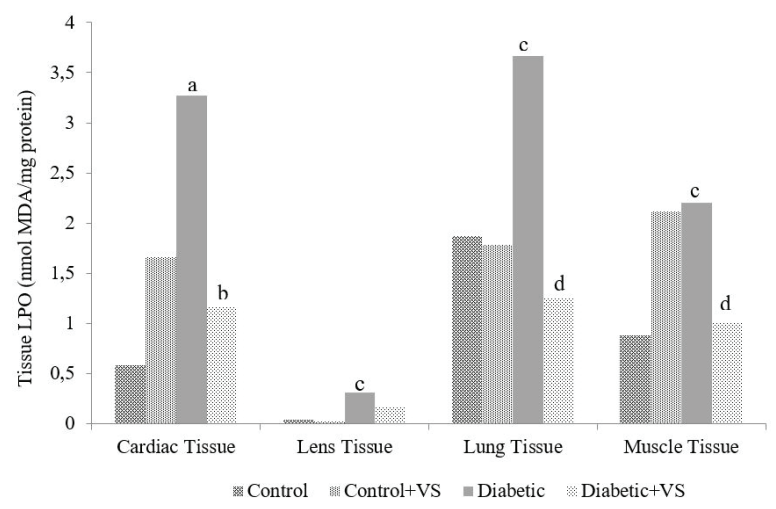

Figure 2. Effects of vanadyl sulfate on LPO levels of cardiac, lens, lung and muscle tissues for all groups.

${ }^{a} P<0.005$ comparing to control group; ${ }^{b} P<0.05$ comparing to diabetic group; ${ }^{c} P<0.0001$ comparing to control group; $d P<0.0001$ comparing to diabetic group.

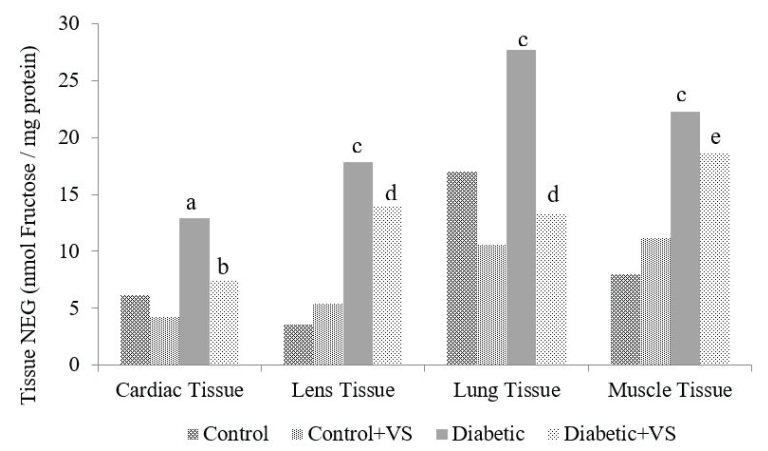

Figure 3. Effects of vanadyl sulfate on NEG levels of cardiac, lens, lung and muscle tissues for all groups.

${ }^{a} P<0.005$ comparing to control group; ${ }^{b} P<0.05$ comparing to diabetic group: ${ }^{c} P<0.0001$ comparing to control group; ${ }^{d} P<0.0001$ comparing to diabetic group; eP<0.001 comparing to diabetic group.

\section{Lens tissue}

The GSH levels of lens tissue for all groups are also given in Figure 1. The GSH was significantly lowered in diabetic groups when compared to controls $(c P<0.0001)$. The administration of VS to the diabetic groups increased the lens GSH levels $\left({ }^{d} P<0.0001\right)$. Lens LPO levels in the diabetic group was significantly increased $\left({ }^{c} P<0.0001\right)$. On the other hand, there was no significant decrease in LPO levels in the VS given diabetic group compared to the diabetic rats (Figure 2). The NEG level was significantly increased in diabetic groups when compared to controls ( $\left.{ }^{c} P<0.0001\right)$. Oral administration of VS significantly decreased the level of NEG in the diabetic lens tissue $\left({ }^{d} P<0.0001\right)$.

\section{Lung tissue}

The mean lung tissue GSH levels for all four groups are given in Figure 1. The lung GSH levels were significantly reduced in diabetic animals when compared to controls ( $\left.{ }^{c} P<0.0001\right)$. Oral application of VS significantly increased the GSH level on the 60 day. ( $\left.{ }^{\mathrm{d}} P<0.0001\right)$. This situation is opposite for lung LPO and NEG levels as seen in Figure 2 and Figure 3. There was a significant increase in LPO and NEG values in the diabetic group compared to the control group $\left({ }^{c} P<0.0001\right.$; $\left.{ }^{c} P<0.0001\right)$. Upon the administration of VS to the diabetic group, both LPO and NEG values decreased in the VS treated diabetic rats $\left({ }^{d} P<0.0001,{ }^{d} P<0.0001\right)$.

\section{Skeletal muscle tissue}

As seen in Figure 1, a meaningful decrease in the muscle tissue GSH levels was seen in STZ-induced diabetic animals when compared to controls $\left({ }^{c} P<0.0001\right)$. Administration of VS to diabetic rats restored the elevated GSH level in muscle tissue $\left({ }^{d} P<0.0001\right)$. As shown in Figures 2 and 3, muscle LPO and NEG levels increased in the diabetic groups compared to that of the control groups ( $\left.{ }^{c} P<0.0001,{ }^{c} P<0.0001\right)$.

Oral vanadium solution caused decreased LPO and NEG levels in diabetic rats $\left({ }^{\mathrm{d}} P<0.0001,{ }^{e} P<0.001\right)$.

\section{DISCUSSION}

DM is a major risk factor for cardiovascular, corneal, respiratory and skeletal muscle diseases. Oxidative stress is known to precipitate the improvement of diabetes and its pathological events (Hajarnavis \& Bulakh, 2019). Increased oxidative injury impairs the enzymatic defense system against reactive oxygen species. This is evidenced by the significant decrease of various antioxidant parameters in experimental diabetic models of various tissues.

According to the oxidative stress hypothesis, chronic complications of diabetes leads to the imbalance between antioxidant defense capacity and the rate of formation of reactive oxygen species and free radicals. In other words, hyperglycemia induces oxidative stress (Cayir et al., 2015).

Vanadium helps the antioxidant system by restoring oxidative conditions and inhibiting lipid peroxidation. This improved oxidative status is a result of reduced superoxide, hydroxyl radicals and free radicals and intracellular reactive oxygen spaces by vanadium ions. Vanadium also has the capability to restore insulin susceptibility in different types of diabetes (Tariq et al., 2020). In our previous studies, it was reported that VS and oxovanadium (IV) complex based on S-methylthiosemicarbazone have protective effects on pancreatic islet $\beta$ cells via insulin-mimetic activity (Bolkent, Bolkent, Yanardag, \& Tunali, 2005; Yanardag et al., 2009). In the light of these findings, this study was aimed to investigate the effects of VS on a large increase in oxidative stress of different tissues and serum parameters in diabetic rats. 
The lipid profile and protein degradation of diabetic patients is changed strongly compared to non diabetics. The changes in cholesterol and triglyceride levels partially cause increase in the levels of atherosclerotic disease and myocardial infarction in diabetic individuals. Our data shows that diabetic oxidative injury increased serum total lipid and total protein levels in the diabetic group. The antidiabetic effects of vanadium via oral administration in rats lowered these parameters. The present finding is in agreement with previous studies which involved long term vanadate treatments in diabetic animals. According to these studies, vanadium treatment improved various serum lipid parameters along with its antidiabetic properties (Sekar \& Govindasamy, 1991; Gupta, Raju, Prakash, \& Baquer, 1999; Ding et al., 2001).

Diabetes is the main reason of cardiovascular morbidity and mortality. Today, it is known that the risk of heart failure increases in diabetic patients even if there is an improvement in coronary artery disease and hypertension (El Hadi, Vettor, \& Rossato, 2019). The increases of ROS generation and even their accumulation, plays a crucial role in cardiomyocyte apoptosis (Cai et al., 2002). This causes antioxidant defense systems such as GSH - a major intracellular antioxidant that plays a key role in reducing the effects of oxidative stress - to be depleted in the atrium of diabetic hearts (Townsend, Tew, \& Tapiero, 2003; Lutchmansingh et al., 2018). Cayir et al. (2015) demonstrated that there is a significant reduction in GSH level in diabetes related pulmonary injury. According to Yang et al. (2020), GSH level is an important indicator of antioxidant capacity, and GSH level in the lens tissue of four week STZ induced diabetic rats decreased. In our research, all tissues of the hyperglycemic group showed significantly decreased GSH levels when compared to control groups. In response to oral administration of VS, a positive role of VS to the antioxidant system by increasing GSH level was observed in all tissues. The ameliorative effects of vanadium against oxidative stress may be due to its influential power on cellular GSH level and up regulated mRNA. Protein expression of a catabolytic subunit of glutamate cysteine ligase is directly related to the synthesis of this tripeptide (Kim et al., 2011).

Diabetes induces disturbances of lipid profiles, especially an increased susceptibility to lipid peroxidation, which is responsible for major complication in various tissues of DM (Lu, 1999; Akgun-Dar, Bolkent, Yanardag, \& Tunali, 2007; Tunali \& Yanardag, 2013). In chronic diseases, such as DM2 and its complications, there is usually excessive formation of MDA (Rehman \& Akash, 2017). Djelić et al. (2019) reported that lipid peroxidation may also be an important mediator of DNA damage related to oxidative stress caused by reactions of adrenaline and a higher level of glucose. In human cortical and nuclear cataract, MDA has been found to increase by 3.5 and 2.5 times respectively than the normal levels (Anderson, Rapp, \& Wiegand, 1984; Griesmacher et al., 1995). Lung and muscle are also target organs in patients with either type 1 or type 2 DM (Li, Song, Wang, Meng, \& Cui, 2018). Previous studies have indicated that diabetic hyperglycemia damages the respiratory system causing physiological and structural pulmonary alterations (Messner, Lundberg, \&Wikström, 2003; Dennis et al.,
2010), and restrictive ventilatory dysfunction helps to facilitate the development of type 2 DM (Kim, Zhang, Kang, You, \& Hyun, 2015). Szkudelska et al. (2019) demonstrated that accumulated lipid levels in Goto-Kakizaki diabetic rats significantly increased when compared to control rats. This was due to insulin dependent glucose uptake by skeletal muscles in physiological conditions. Moreover, insulin resistance in the skeletal muscle is thought to be the main failure in DM2, whereas reduced lipid accumulation in this tissue, with a concomitant improvement of intramuscular glucose carriage, shows a favorable effect on whole body glucose metabolism (Szkudelska et al., 2019).

In the present study, a significant difference was observed when the MDA (the final products of lipid peroxidation) levels of the groups were compared; MDA levels were higher in the diabetic groups of all studied tissues than in the control groups. This shows that MDA level is a priority marker of diabetic inflammatory and oxidative damage response. It decreased upon administration of VS and that suppressed inflammation and oxidative damage. The reversion of this process after treatment with VS is likely due to reduction in damage resulting from the oxidative stress demonstrated by cardiac, lens, lung and skeletal muscle lipid peroxidation.

Advanced glycation end products (AGEs) pathway is one of the four important pathways associated with chronic complications of DM (Naso et al., 2010). Formation of AGEs as a result of NEG, is a nonenzymatic reaction between the carbonyl group of reducing sugars and the free amino residues of proteins, lipids, or nucleic acids (Singh, Barden, Mori, \& Beilin, 2001). These products are also complex heterogeneous compounds with fluorescent and non-fluorescent characters such as $\mathrm{N} \varepsilon$-carboxymethyl lysine, Nc-carboxyethyl lysine, pentoside, argpyrimidine, glyoxal lysine dimer and methyl glyoxal lysine dimer (Bohlin et al., 2013; Lavelli, Sri Harsha, Ferranti, Scarafoni, \& lametti, 2016; Chen et al., 2019). In our study, a significant alteration of cardiac, lens, lung and skeletal muscle tissues NEG levels were observed in diabetic rats. This is also an indicator of the oxidative stress damage caused by diabetes on these tissues. In the diabetic lens tissue, AGEs induces higher crosslinking of corneal collagen fibrils and proteoglycans thereby resulting in the development of cataract (Bao et al., 2017; Hajarnavis \& Bulakh, 2019). Although lung tissue has evolved several mechanisms to attenuate oxidative stress (Otoupalova, Smith, Cheng, \& Thannickal, 2020), they are the most affected in higher hyperglycemic conditions and uniquely exposed to a highly oxidizing environment. Abnormal glucose metabolism causes the production of AGEs which are primarly related with increased NEG level in this tissue. The increased NEG levels in cardiac and skeletal muscle tissues in diabetic rats are another important event for progression of DM pathogenesis. Crosslinking involving elastin and collagen can cause impaired relaxation and increased stiffness in myocardial and skeletal muscle tissues (Lee \& Kim, 2017). In the present study, VS suppressed NEG levels of all the studied tissues in the diabetic group by acting as an antioxidant and effective insulin mimetic agent. These effects of vanadium sulfate on diabetic rats are in agreement with our previous studies (Tunali \& Yanardag, 2006; Yanardag \& Tunali, 2006). 


\section{CONCLUSION}

Diabetic experimental animal models exhibit abrupt generation of free radical and oxidative stress due to persistent chronic hyperglycemia. The current study demonstrated that VS may exert potent protective functions against oxidative damage in tissues of STZ-induced diabetic rats with associated biochemical alterations. It was also observed that treatment with VS significantly restored some oxidative stress parameters and can be used as a more efficacious antioxidant and antidiabetic agent by suppresing the oxidative stress in oxidatively damaged diabetic rat tissues.

Peer-review: Externally peer-reviewed.

Author Contributions: Conception/Design of Study- S.T., R.Y.; Data Acquisition- S.T., R.Y.; Data Analysis/Interpretation- S.T., R.Y.; Drafting Manuscript- S.T., R.Y.; Critical Revision of Manuscript- S.T., R.Y.; Final Approval and Accountability- S.T., R.Y.

Conflict of Interest: The authors have no conflict of interest to declare.

Financial Disclosure: The Scientific Research Projects Coordination Unit of Istanbul University (Project number: T-936/06112000) supported this work.

\section{REFERENCES}

- $\quad$ Akgun-Dar, K., Bolkent, S. Yanardag, R., \& Tunali, S. (2007). Vanadyl sulfate protects against streptozotocin-induced morphological and biochemical changes in rat aorta. Cell Biochemistry \& Function, 25, 603-609.

- $\quad$ Anderson, R. E., Rapp, L. M., \& Wiegand, R. D. (1984). Lipid peroxidation and retinal degeneration. Current Eye Research, 3, 223-227.

- Bao, F. J., Deng, M. L., Zheng, X. B., Li, N. A., Zhao, Y. P. Cao, S. Yua, A., Wang, Q. M., Huang, J. H., \& Elsheikh, A. (2017). Effects of diabetes mellitus on biomechanical properties of the rabbit cornea. Experimental Eye Research, 161, 82-88.

- Beutler, E. (1975). Glutathione in red blood cell metabolism; In A manual of biochemical methods, 2nd ed. Grune and Stratton, New York, pp. 112-114.

- Bohlin, C., Praestgaard, E., Baumann, M. J., Borch, K., Praestgaard, J., Monrad, R. N., \& Westh, P. (2013). A comparative study of hydrolysis and transglycosylation activities of fungal a-glucosidases. Applied Microbiology and Biotechnology, 97, 159-169.

- Bolkent, S., Bolkent, S., Yanardag, R., \& Tunali, S. (2005). Protective effect of vanadyl sulfate on the pancreas of streptozotocininduced diabetic rats. Diabetes Research and Clinical Practice, 70, 103-109.

- Cai, L., Li, W., Wang, G., Guo, L., Jiang, Y., \& Kang, Y. J. (2002). Hyperglycemia-induced apoptosis in mouse myocardium: mitochondrial cytochrome C-mediated caspase-3 activation pathway. Diabetes, 51, 1938-1948.

- Cayir, A., Ugan, R. A., Albayrak, A. D., Kose, E., Akpinar, Y., Cayir, H. T., Atmaca, Bayraktutan Z., \& Kara M. (2015). The lung endothelin system: a potent therapeutic target with bosentan for the amelioration of lung alterations in a rat model of diabetes mellitus. Journal of Endocrinological Investigation, 38, 987-998.

- Chen, Y., Tanga, S., Chend, Y., Zhang, R., Zhoua, M., Wanga, C., Fenga, N., \& Wu, Q. (2019). Structure-activity relationship of procyanidins on advanced glycation end products formation and corresponding mechanisms. Food Chemistry, 279, 679-687.
- Dennis, R. J., Maldonado, D., Rojas, M. X., Aschner, P., Rondón, M., Charry, L., \& Casas, A. (2010). Inadequate glucose control in type 2 diabetes is associated with impaired lung function and systemic inflammation: a cross-sectional study. BioMed Central, 10, 38.

Djelić, N., Radaković, M., Borozan, S., Dimirijević-Srećković, V., Pajović, N., Vejnović, B., Borozan, N., Bankoglu, E. E., Stopper, H., \& Stanimirović, Z. (2019). Oxidative stress and DNA damage in peripheral blood mononuclear cells from normal, obese, prediabetic and diabetic persons exposed to adrenaline in vitro. Mutation Research - Genetic Toxicology and Environmental Mutagenesis, 843, 81-89.

- $\quad$ Ding, W., Hasegawa, T., Hosaka, H., Peng, D., Takahashi, K., \& Seko, Y. (2001). Effect of long-term treatment with vanadate in drinking water on KK mice with genetic non-insulin-dependent diabetes mellitus. Biological Trace Element Research, 80, 159-174.

- Domingo, J. L., \& Gómez, M. (2016). Vanadium compounds for the treatment of human diabetes mellitus: A scientific curiosity? A review of thirty years of research. Food and Chemical Toxicology, 95, 137-141.

- $\quad$ El Hadi, H., Vettor R., \& Rossato, M. (2019). Cardiomyocyte mitochondrial dysfunction in diabetes and its contribution in cardiac arrhythmogenesis. Mitochondrion, 46, 6-14.

Frings, C. S., Fendley, T. W., Dunn, R. T. \& Queen C. A. (1972). Improved determination of total serum lipids by the sulfo-phosphovanillin reaction. Clinical Chemistry, 18, 673-674.

Griesmacher, A., Kindhauser, M., Andert, S. E., Schreiner, W., Toma, C., Knoebl, P., Pietschmann, P., Prager, R., Schnack, C., Schemthaner, G., \& Mueller, M. M. (1995). Enhanced serum levels of thiobarbituric-acid-reactive substances in diabetes mellitus. The American Journal of Medicine, 98, 469-475.

Gupta, D., Raju, J., Prakash, J., \& Baquer, N. Z. (1999). Change in the lipid profile, lipogenic and related enzymes in the livers of experimental diabetic rats: effect of insulin and vanadate. Diabetes Research and Clinical Practice, 46, 1-7.

- Hajarnavis A. M., \& Bulakh P. M. (2019). Anticataract effects of S. cumini and A. marmelos on goat lenses in an experimental diabetic cataract model, Journal of Ayurveda and Integrative Medicine, https://doi.org/10.1016/j.jaim.2019.08.001.

- Heyliger, C. E., Tahiliani, A. G., \& McNeill, J. H. (1985). Effect of vanadate on elevated blood glucose and depressed cardiac performance of diabetic rats. Science, 227, 1474-1477.

Irving E., \& Stoker A. W. (2017). Vanadium compounds as PTP inhibitors. Molecules, 22, 2269.

- Jound, A., Lambert, E., Stauffacher, W., \& Renold, A. E. (1969). Diabetogenic action of streptozotocin. Relationship of dose to metabolic response. Journal of Clinical Investigation, 48, 2129-2139.

- $\quad$ Kim, A. D., Zhang, R., Kang, K. A., You, H. J., \& Hyun, J. W. (2011). Increased glutathione synthesis following Nrf2 activation by vanadyl sulfate in human chang liver cells. International Journal of Molecular Sciences, 12, 8878-8894.

Kim, C. H., Kim, H. K., Kim, E. H., Bae, S. J., Jung, Y. J., Choi, J., \& Park, J. Y. (2015). Association of restrictive ventilatory dysfunction with the development of prediabetes and type 2 diabetes in Koreans. Acta Diabetologica, 52, 357-363.

- Lavelli, V., Sri Harsha, P. S. C., Ferranti, P., Scarafoni, A., \& lametti, S. (2016). Grape skin phenolics as inhibitors of mammalian a-glucosidase and a-amylase effect of food matrix and processing on efficacy. Food \& Function, 7, 1655-1663.

Ledwozyw, A., Michalak, J., Stepien, A., \& Kadziolka, A. (1986). The relationship between plasma triglycerides, cholesterol, total lipids and lipid peroxidation products during human atheroschlerosis. Clinica Chimica Acta, 155, 275-283.

Lee, W. S., \& Kim, J. (2017). Diabetic cardiomyopathy: where we are and where we are going. The Korean Journal of Internal Medicine, $32,404-421$ 
- Li, D., Song, L. L., Wang, J., Meng, C. \& Cui, X. G. (2018). Adiponectin protects against lung ischemia-reperfusion injury in rats with type 2 diabetes mellitus. Molecular Medicine Reports, 17, 71917201.

- Li, J., \& Lian, H. (2016). Recent development of single preparations and fixed-dose combination tablets for the treatment of non-insulin-dependent diabetes mellitus. Archives of Pharmacal Research, 39, 731-746.

- Lowry, O. H., Rosebrough, W. I., Farr, A. L., \& Randal R. J. (1951). Protein measurement with the folin phenol reagent. Journal of Biological Chemistry, 193, 265-275.

- Lu, S. C. (1999). Regulation of hepatic glutathione synthesis: current concepts and controversies. Federation of American Societies for Experimental Biology Journal, 13, 1169-1183.

- Lutchmansingh, F. K., Hsu J. W., Bennett, F. I., Badaloo, A. V., McFarlane-Anderson, N., Gordon-Strachan, G. M., Wright- Pascoe R. A., Jahoor, F., \& Boyne M. S. (2018). Glutathione metabolism in type 2 diabetes and its relationship with microvascular complications and glycemia. Public Library of Science One, 13, e0198626.

- Messner, T., Lundberg, V., \& Wikström, B. (2003). The Arctic Oscillation and incidence of acute myocardial infarction. Journal of Internal Medicine, 253, 666-670.

- Naso, F. C., Mello, R. N., Bona, S., Dias, A. S., Porawski, M., Ferraz, A. B. F., Richter, M. F. R., \& Marroni N. P. (2010). Effect of Agaricus blazei Murill on the pulmonary tissue of animals with streptozotocininduced diabetes. Experimental Diabetes Research, 2010, https:// doi.org/10.1155/2010/543926.

- $\quad$ Newsholme, P., Cruzat, V.F., Keane, K.N., Carlessi R., \& Bittencourt, P.I.H. (2016). Molecular mechanisms of ROS production and oxidative stress in diabetes. Biochemical Journal, 473, 4527-4550.

- Otoupalova, E., Smith, S., Cheng, G., \& Thannickal, V. (2020). Oxidative stress in pulmonary fibrosis. Comprehensive Physiology, 10, 509-547.

- $\quad$ Pal, R.P., Mani, V., Tripathi, D., \& Datt, C. (2018). Inorganic vanadium supplementation in crossbred calves: effects on antioxidant status, immune response and haemato-biochemical attributes. Biological Trace Element Research, 186, 154-161.

- $\quad$ Parker, K.M., England, J.D., Casto, J.D., Hessel, R., \& Goldstein, P.E. (1981). Improved colorimetric assay for glycosylated hemoglobin. Clinical Chemistry, 27, 669-672.

- $\quad$ Rehman, K., \& Akash, M. S. H. (2017). Mechanism of generation of oxidative stress and pathophysiology of type 2 diabetes mellitus: How are they interlinked? The Journal of Cellular Biochemistry, 118, 3577-3585.
Sekar, N., \& Govindasamy, S. (1991). Effects of vanadate on plasma lipoprotein profiles in experimental diabetic rats. International Journal of Biochemistry, 23, 935-940.

- $\quad$ Singh, R., Barden, A., Mori, T., \& Beilin, L. (2001). Advanced glycation end products: a review. Diabetologia, 44,129-146.

- $\quad$ Szkudelska, K., Deniziak, M., Hertig, I., Wojciechowicz, T., Tyczewska, M., Jaroszewska, M., \& Szkudelski, T. (2019). Effects of resveratrol in goto-kakizaki rat, a model of type 2 diabetes. Nutrients, 11, 2488.

- Tariq H., Sharma, A., Sarkar, S., Ojha, L., Pal R. P., \& Mani V. (2020). Perspectives for rare earth elements as feed additive in livestock - A review. Asian-Australas The Journal of Animal Science, 33, 373381.

- $\quad$ Townsend, D. M., Tew, K. D., \& Tapiero, H. (2003). The importance of glutathione in human disease. Biomedicine \& Pharmacotherapy, $57,145-155$

- Tunali, S., \& Yanardag, R. (2006). Effect of vanadyl sulfate on the status of lipid parameters and on stomach and spleen tissues of streptozotocin-induced diabetic rats. Pharmacological Research, 53, 271-277

- Tunali, S., \&Yanardag, R. (2013). Protective effect of vanadyl sulfate on skin injury in streptozotocin-induced diabetic rats. Human and Experimental Toxicology, 32, 1206-1212.

- Yanardag, R., \& Tunali, S. (2006). Vanadyl sulfate administration protects the streptozotocin-induced oxidative damage to brain tissue in rats. Molecular and Cellular Biochemistry, 286, 153-159.

- $\quad$ Yanardag, R., Demirci, T.B., Ulküseven, B., Bolkent, S., Tunali, S., \& Bolkent, S. (2009). Synthesis, characterization and antidiabetic properties of N(1)-2,4-dihydroxybenzylidene-N(4)-2-hydroxybenzylidene-S-methyl-thiosemicarbazidato-oxovanadium(IV). European Journal of Medicinal Chemistry, 44, 818-826.

- Yang, J. F., Gong, X., Bakh, N.A., Carr, K., Phillips, N.F.B., Ismail-Beigi, F., Weiss, M. A., \& Strano, M. S. (2020). Connecting rodent and human pharmacokinetic models for the design and translation of glucose-responsive insulin. Diabetes, doi: 10.2337/db19-0879.

- Yilmaz-Ozden, T., Kurt-Sirin, O., Tunali, S., Akev, N., Can. A., \& Yanardag, R. (2014). Ameliorative effect of vanadium on oxidative stress in stomach tissue of diabetic rats. Bosnian Journal of Basic Medical Sciences, 14, 105-109. 